\title{
Insulin Like Growth Factor-1 Measurement
}

National Cancer Institute

\section{Source}

National Cancer Institute. Insulin Like Growth Factor-1 Measurement. NCI Thesaurus. Code C74864.

The determination of the amount of insulin-like growth factor-1 present in a sample. 